\title{
Solitary mastocytoma: A rare presentation on the buccal mucosa
}

\author{
Bogahawatte Samarakoon Mudiyanselage Samadarani Siriwardena ${ }^{1}$, \\ Ruwan Duminda Jayasinghe ${ }^{2}$, Neelakanthi Ratnatunga ${ }^{3}$, \\ Wanninayake Mudiyanselage Tilakaratne ${ }^{1}$
}

\footnotetext{
${ }^{1}$ Department of Oral Pathology, Faculty of Dental Sciences, University of Peradeniya, Peradeniya, Sri Lanka; Corresponding Author: samadarani@yahoo.com

${ }^{2}$ Department of Oral Medicine and Periodontology, Faculty of Dental Sciences, University of Peradeniya, Peradeniya, Sri Lanka

${ }^{3}$ Department of Pathology, Faculty of Medicine, University of Peradeniya, Peradeniya, Sri Lanka
}

Received 11 February 2013; revised 15 March 2013; accepted 10 April 2013

Copyright (c) 2013 Bogahawatte Samarakoon Mudiyanselage Samadarani Siriwardena et al. This is an open access article distributed under the Creative Commons Attribution License, which permits unrestricted use, distribution, and reproduction in any medium, provided the original work is properly cited.

\begin{abstract}
Mastocytoma usually presents as a solitary lesion whereas mastocytosis is a rare skin condition which typically manifests with or without accompanied systemic symptoms. Although a few cases of solitary mastocytoma have been documented on mucosa (vulva), none has been reported on the oral mucosa in the English literature. The present case is an example of an exceptional rare presentation of solitary mastocytoma of the oral mucosa.
\end{abstract}

Keywords: Solitary Mastocytoma; Oral Mucosa

\section{INTRODUCTION}

Mastocytoma usually presents as a solitary lesion whereas mastocytosis is a rare skin condition which typically manifests with or without accompanied systemic symptoms. It is estimated that up to $10 \%$ to $15 \%$ of patients with mast cell disorders may develop a solitary mastocytoma without systemic involvement [1]. Although, a few cases of solitary mastocytoma have been documented on mucosa (vulva), none has been reported on the oral mucosa in the English literature. The prevalence of this lesion is higher in children and rare in older age. We report the first case of solitary mastocytoma in the oral cavity in a 20 yrs old female who presented with a lump on the buccal mucosa.

\section{CASE REPORT}

A 20 years old otherwise healthy female presented with a complaint of an asymptomatic lump for 3 years duration on the buccal mucosa to Oral Medicine clinic, Dental Hospital, Peradeniya, Sri Lanka. On examination it was a firm, painless nodule of $0.75 \mathrm{~cm} \times 0.75 \mathrm{~cm}$ and the colour was similar to normal oral mucosa. It was smooth surfaced and well defined with intact overlying mucosa. None of the inflammatory signs were found in the lesion. Any history of trauma could not be elicited. As the nodule was small, excisional biopsy was performed without an incisional biopsy with the clinical diagnosis of either a reactive fibroepithelial lesion or enlarged facial lymph node. Histopathologically, the lesion was composed of solid sheets of mast cells containing abundant eosinophilic cytoplasm. There was a marked infiltrate of eosinophils in between the main cell population (Figure 1). These cells were confirmed as mast cells with the special stain Toluidine blue (Figure 2). All the hematological investigations which were carried out appeared to be within normal limits and there was no organomegaly and the patient is on regular follow up. There is no evidence of recurrence during the follow up period of more than 8 months.

\section{DISCUSSION}

Mastcytosis is a rare disease characterized by abnormally increased numbers of mast cells in tissues. WHO classifies mastocytosis as cutaneous mastocytosis (urticaria pigmentosa), indolent systemic mastocytosis, systemic mastocytosis with an associated (clonal) hematologic non-mast cell lineage disease, aggressive systemic mastocytosis, mast cell leukemia, mast cell sarcoma and extra cutaneous mastocytoma [2]. Types of cutaneous mastocytosis include solitary mastocytoma, diffuse cutaneous mastocytosis, Maculopapular cutane- 
ous mastocytosis and urticaria pigmentosa (UP).

Although solitary mastocytoma mostly occurs in young children, it rarely manifests in adults. The lesions are usually cutaneous and involve the face, trunk and extremities. To the best of our knowledge, this is the first case of solitary mastocytoma reported in the oral cavity. There are no specific signs and symptoms which may help the clinicians to include SM in the differential diagnosis of an oral mucosal lump. As it is a non-descript lump of normal mucosal colour, the differential diagnosis would be one of fibroepithelial lesions. However, the diagnosis is necessarily histopathological for the solitary lesion. Then, it is the duty of the clinician to exclude possible systemic involvement by performing bone marrow examination. Although mastocytoma in the oral mucosa is uncommon in humans many cases have been reported in animals such as dogs, cats and cattle [3]. Cutaneous mastocytosis (CM) is often diagnosed in child-

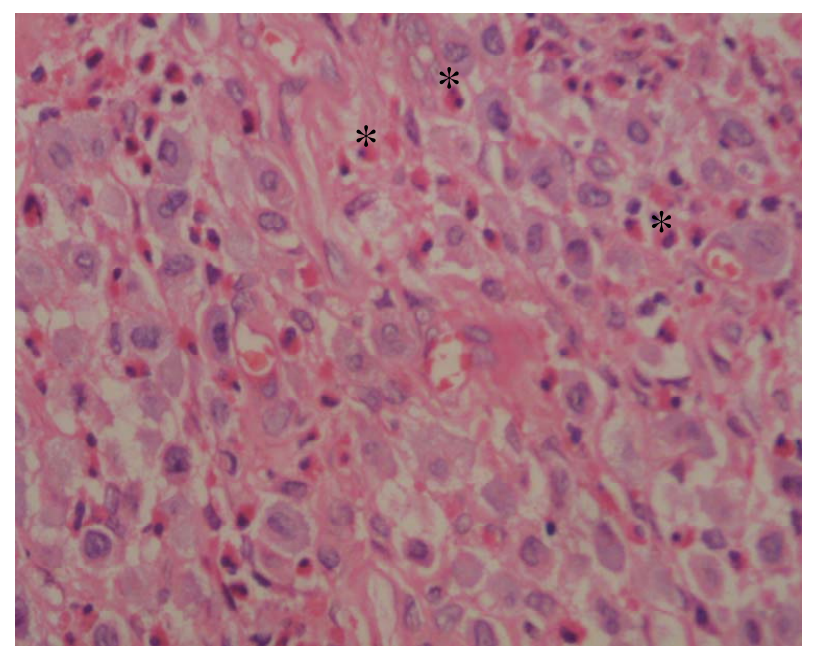

Figure 1. Sheets of mast cells admixed with eosinophils $\left(^{*}\right)(\mathrm{H}$ \& $\mathrm{E} \times 200)$.

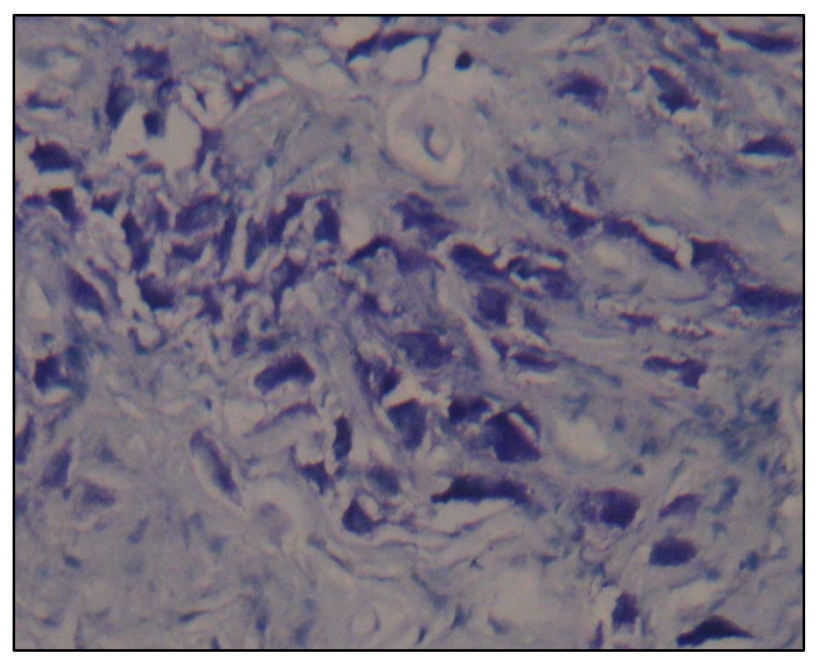

Figure 2. Mast cells stained with Toluidine blue $(\times 400)$. hood and less frequently reported in adults [4]. However, in adult patients systemic mastocytosis (SM) is more frequently diagnosed than CM [5].

The diagnosis of SM is established with the examination of bone marrow [6] and other organs such as liver and gastrointestinal tract $[7,8]$. Pediatric CM may regress spontaneously in a significant number of cases [2] or disappear before or during puberty. Therefore, in pediatric patients a bone marrow examination is not required unless organomegaly or significant peripheral blood abnormalities are present. If present, measurement of serum tryptase is indicated before bone marrow examination. The serum tryptase concentration is greater than 20 $\mathrm{ng} / \mathrm{ml}$ in most SM patients [8]. The present case which was on the buccal mucosa did not show any signs of regression despite the fact that it was present for three years.

The present case is an example of a very rare presentation of solitary mastocytoma of the oral mucosa.

\section{REFERENCES}

[1] Castells, M.C. (2006) Extracutaneous mastocytoma. Journal of Allergy and Clinical Immunology, 117, 15131515. doi:10.1016/j.jaci.2006.04.016

[2] Valent, P., Horny, H.-P., Li, C.Y., Longley, J.B., Metcalfe, D.D., Parwaresch, R.M., et al. (2001) Mastocytosis (mast cell disease). World Health Organization (WHO) classification of tumours. Pathology and genetics. In: Jaffe, E.S., Harris, N.L., Stein, H., Vardiman, J.W., Eds., Tumours of Haematopoietic and Lymphoid Tissues, Vol. 1. IARC Press, Lyon, 291-302.

[3] Moulton, J.E. (1978) Tumors in domestic animals. University of California Press, Los Angeles.

[4] Valent, P., Akin, C., Sperr, W.R., Horny, H.P., Arock, M., Lechner, K., et al. (2003) Diagnosis and treatment of systemic mastocytosis: State of the art. British Journal of Haematology, 122, 1-23. doi:10.1046/j.1365-2141.2003.04575.x

[5] Horny, H.P. and Valent, P. (2002) Histopathological and immunophenotypical aspects of mastocytosis. International Archives of Allergy and Immunology, 127, 115-117. doi:10.1159/000048180

[6] Horny, H.-P., Ruck, M. and Kaiserling, E. (1992) Spleen findings in generalized mastocytosis. A clinicopathologic study. Cancer, 70, 459-468.

doi:10.1002/1097-0142(19920715)70:2<459::AID-CNC $\underline{\text { R2820700214 }>3.0 . C O ; 2-4}$

[7] Horny, H.-P., Kaiserling, E., Parwaresch, M.R. and Lennert, K. (1992) Lymph node findings in generalized mastocytosis. Histopathology, 21, 439-446. doi:10.1111/j.1365-2559.1992.tb00428.x

[8] Schwartz, L.B., Sakai, K., Bradford, T.R., Ren, S., Zweiman, B., Worobec, A.S., et al. (1995) The alpha form of human tryptase is the predominant type present in blood at baseline in normal subjects and is elevated in those with systemic mastocytosis. Journal of Clinical Investigation, 96, 2702-2710. doi:10.1172/JCI118337 